DOI: 10.14451/1.175.62

\title{
ЦИФРОВАЯ ЭКОНОМИКА: ОГРАНИЧЕНИЯ И ПЕРСПЕКТИВЫ ВНЕДРЕНИЯ
}

\author{
(C) 2019 Мясоедов Сергей Александрович \\ доктор экономических наук, доцент \\ Академия маркетинга и социально-информационных технологий - ИМСИТ, Россия, Краснодар \\ E-mail: myasoedov8@mail.ru
}

Интернет, виртуальная реальность, эффективность цифровых технологий стёрли границы государств, сделали людей ближе, но при этом появление цифровых продуктов создало и значительное число угроз и проблем общепринятым устоям, образу жизни, трансформировали экономическую деятельность. Шеринговая экономика ставит под сомнение необходимость приобретения в собственность активов; технологии больших данных позволяют выстроить причинно-следственную взаимосвязь между событиями, которые никогда не признавались ранее взаимозависимыми; интернет вещей делает жизнь комфортной, снижает уровень потребления ресурсов, но отнимает право личного пространства, - цифровая экономика активно завоёвывает новые позиции в социальном и экономическом пространстве.

Ключевые слова: цифровая экономика, ограничения, интернет вещей, большие данные, шеринговая экономика.

Экономические отношения постоянно развиваются, создавая основу для перехода к следующему технологическому укладу.

Интенсивное развитие информационных технологий позволило вести речь о появлении новых экономических отношений неразрывно связанных с электронной (виртуальной) средой и о зарождении нового вида экономики - цифровой экономики.

Выделяют следующие основные рубежи развития экономических процессов в электронной среде (этапы формирования цифровой экономики):

1. Глобализация интернета, осоциализация интернета.

2. Дублирование, перевод всей информации о деятельности хозяйствующих субъектов из реальной (физической) среды в виртуальную (электронную) среду.

3. Появление и внедрение системы электронных платежей, электронных (над государственных) денег, электронных товаров (программные продукты, компьютерные игры, электронные книги, дистанционное образование, медицина, управление городскими системами и т.д.) [4, С. 9].

В настоящее время цифровую экономику сегментируют на три составляющие:

- шеринговая экономика (sharing economy) включает два больших элемента: экономику временного обмена (Freemium) ненужными в данный момент вещами (аренда жилья, авто и т.д.) и экономику совместного управления имуществом (co-living).

- технологии больших данных (BigData), связанных с развитием технологий искусственного интеллекта, бизнес аналитики, имитационного моделирования, прогнозирования, анализа неструктурированных данных и т.д.

- технологии интернета вещей (Internet of Things, IoT) применяют массово в технологически развитых государствах мира в энергетике, медицине, сельском хозяйстве, логистике, в управлении городской средой, технологиях «Умный дом».

Основными ограничивающими факторами внедрения достижений цифровой экономики считается несовершенство законодательства, значительная стоимость цифровых технологий и их обслуживание, отказ социума принимать предложенные новые нормы и правила, кибер угрозы, связанные с ростом возможностей доступа к конфиденциальной информации, потерей активов.

Для Российской Федерации дополнительным сдерживающим фактором внедрения цифровых технологий считается низкий уровень доходов россиян, в сравнении с уровнем доходов граждан развитых государств мира, что и подтвердил общественный резонанс от всероссийской акции по переходу с аналогового телевидения на цифровое вещание. 
Таблица 1. Оценка уровня влияния факторов на скорость внедрения цифровых технологий

\begin{tabular}{|c|c|c|c|c|}
\hline \multirow{2}{*}{ Сегменты цифровой экономики } & \multicolumn{4}{|c|}{$\begin{array}{c}\text { Уровень влияния факторов, ограничивающих темпы } \\
\text { внедрения цифровых технологий }\end{array}$} \\
\hline & юридические & $\begin{array}{c}\text { экономи- } \\
\text { ческие }\end{array}$ & технические & социальные \\
\hline \multicolumn{5}{|l|}{ 1. Шеринговая экономика, в том числе } \\
\hline Экономика временного обмена & Высокий & Низкий & Средний & Высокий \\
\hline Экономика совместного управления & Высокий & Низкий & Средний & Высокий \\
\hline 2. Технологии больших данных & Средний & Высокий & Высокий & Низкий \\
\hline \multicolumn{5}{|l|}{ 3. Технологии интернет вещей, в том числе } \\
\hline Энергетика & Средний & Средний & Высокий & Низкий \\
\hline Медицина & Высокий & Высокий & Высокий & Высокий \\
\hline Сельское хозяйство & Низкий & Высокий & Средний & Низкий \\
\hline Логистика & Средний & Средний & Высокий & Средний \\
\hline Технологии «Умный город» & Высокий & Высокий & Высокий & Средний \\
\hline Технологии «Умный дом» & Средний & Высокий & Высокий & Высокий \\
\hline
\end{tabular}

Для технологий больших данных главными сдерживающими факторами внедрения и развития остаются:

- высокий уровень экономических затрат на внедрение и обслуживание технологий;

- необходимость наличия соответствующей научно-технической базы, обеспечивающей поступательное развитие технологий BigData.

Обработка больших данных для торговых компаний, телекоммуникационных медиа гигантов, крупных промышленных групп приводит к тому, что в результате выдаются решения неординарные, не принятые в данной бизнес среде и в ряде случаев, ставятся под сомнение. Подобные факты подтверждают наличие фактора недоверия к эффективности подобных технологий. Однако, такие ситуации возникают при отсутствии достаточного объёма информации для работы с технологиями BigData, в чём и выражается ещё один фактор уязвимости применения BigData, a именно, конкурентные преимущества получают государства и корпорации обладающие технологиями генерации информации или имеющие доступ к большим объёмам информации (США, Китай, транснациональные корпорации).

Развитие шеринговой экономики связано прежде всего с трансформацией принятых в обществе социальных отношений, так как в итоге любой человек, владеющий электронным устройством становится активным экономическим агентом. Человек совершенного свободно, используя сайт, электронную платформу, может за минимальную цену стать пассажиром- попутчикомв транспортном средстве, принадлежащего абсолютно незнакомого ему человеку; продать любую вещь, актив, минуя посредников. В ряде европейских государств формируется от-

\section{Таблица 2. Ограничения и факторы повышения интенсивности внедрения технологий больших данных (BigData) [3]}

\begin{tabular}{|c|c|}
\hline Факторы роста и развития & Ограничивающие факторы \\
\hline $\begin{array}{l}\text { - реальный рост конкурентных преимуществ при } \\
\text { использовании технологий BigData; } \\
\text { - накопление и постоянный прогрессирующий рост } \\
\text { крупных массивов информации в телекоммуникаци- } \\
\text { онной сфере; } \\
\text { - постоянное совершенствование элементов облач- } \\
\text { ной инфраструктуры мировыми ИТ-гигантами; } \\
\text { - корректировка законодательства в сторону } \\
\text { снижения порога доступности к конфиденциальной } \\
\text { информации; } \\
\text { - наличие колоссального интереса со стороны биз- } \\
\text { нес сообщества к обработке, накопленного медиа- } \\
\text { материала, относящегося ранее к неструктурирован- } \\
\text { ной информации. }\end{array}$ & $\begin{array}{l}\text { 1. Высокая стоимость разработок по направлению } \\
\text { BigData, } \\
\text { 2. Дефицит кадров, способных вести разработки в } \\
\text { формате BigData. } \\
\text { 3. Законодательные ограничения при работе с лич- } \\
\text { ными, персональными данными граждан. } \\
\text { 4. Наличие проблем совместимости используемых } \\
\text { информационных устройств с технологическими } \\
\text { разработками в области BigData } \\
\text { 5. Недоверие к результатам обработки несистемной, } \\
\text { не связанной информации. } \\
\text { 6. Отсутствие у большинства субъектов минималь- } \\
\text { ных объёмов информации, необходимых для работы } \\
\text { с технологиями BigData }\end{array}$ \\
\hline
\end{tabular}


ношение к институту собственности, как к фактору обременения для современного человека, ставится вопрос об эффективности сообществ, где всё принадлежит всем (квазикоммуна), то есть шеринговая экономика меняет статус труда и капитала в экономических отношениях.

Главными преимуществами моделей экономических отношений, принятых в шеринговой экономике, считаются:

- экономия денежных средств и иных ресурсов, доступность человека к человеку, покупателя к продавцу, снижаются издержки по аренде жилья, офисных помещений, оплаты посредникам;

- возможность заработать без лишней бюрократической волокиты (сдать в аренду (в ряде случаев, без юридического оформления), покупать и продавать);

- возможность общаться по интересам с людьми из разных регионов и стран.

К ограничивающим факторам развития шеринговой экономики относят:

- юридические. Противодействие субъектов реального бизнеса, через изменение законодательства на своих территориях, государствах, в частности в ряде стран введён и действует запрет на функционирование платформ по аренде жилья, заказу такси ит.д.;

- рост риска мошенничества, обмана, хищения актива;

- отсутствие юридической регистрации фактов сдачи и получения в аренду активов, принятия на работу и т.д.

- не готовность людей сдавать в аренду, обмениваться единственным активом (в России).

Технологии интернет вещей улучшают жизнь человека, повышают эффективность работы организаций в энергетике, медицине, сельском хозяйстве, логистике, в городской среде.
Для энергетической сферы технологии интернет вещей считаются доступными и активно применяются во многих странах.

Основных сдерживающим фактором внедрения технологий в энергетику связан с тем, что цифровизация оборудования, в отличии от аналогового открывает доступ к ресурсам энергосети и делает её уязвимой для различных видов кибератак (яркий пример, остановка деятельности ГЭС в Венесуэле).

Здравоохранение по праву считается наиболее ответственной сферой применения IоT- технологий и сопряжено с многочисленными барьерами при их внедрении как с юридической стороны, так и с позиции негативного отношения общества к дистанционному лечению.

Сельское хозяйство в Российской Федерации остаётся мало технологичной отраслью и связано, прежде всего с невысоким уровнем добавленной стоимости на сельскохозяйственную продукцию, то есть с отсутствием необходимого объёма инвестиций.

Логистическая сфера считается одной из перспективной по внедрению IоT-технологий в систему транспортировки грузов, нефти, газа и позволяет значительно экономить и оптимизировать использование ресурсов.

Уменьшение числа автомобильных пробок, бесперебойная, ритмичная работа городского транспорта, улучшения качества воздуха, повышение числа раскрываемости преступлений, рост качества работы жилищно-коммунальных служб - и это то не многое, что достигается от использования ІоТ-технологий в городской среде.

Технологии «Умный дом» пока ещё мало доступны рядовым россиянам, хотя существенно повышают уровень комфорта и снижают число внештатных ситуаций, если забыли выключить

\section{Таблица 3. Ограничения и факторы повышения интенсивности внедрения ІоТ-технологий} в энергетику

\begin{tabular}{|c|c|}
\hline Факторы роста и развития & Ограничивающие факторы \\
\hline $\begin{array}{l}\text { - возможность покупать электричество у любой } \\
\text { генерации и возможность продавать собственные } \\
\text { произведённые излишки электричества (в ряде госу- } \\
\text { дарств мира) } \\
\text { - получение онлайн информации и возможность } \\
\text { выбора периода потребления электричества; } \\
\text { - формирование условий для выравнивания сетевой } \\
\text { нагрузки; } \\
\text { - сокращение числа аварий, времени перегрева } \\
\text { оборудования, как результат снижение потерь элек- } \\
\text { тричества; }\end{array}$ & $\begin{array}{l}\text { - значительные объёмы инвестиций при внедрении } \\
\text { ІоТ-технологий; } \\
\text { - проблемы совместимости цифрового оборудова- } \\
\text { ния, разных платформ; } \\
\text { - дефицит специалистов соответствующей квали- } \\
\text { фикации по установке и обслуживанию ІоТ- } \\
\text { устройств; } \\
\text { - рост потенциала кибер угроз за счёт внедрения } \\
\text { цифровых устройств и роста возможностей для } \\
\text { внешнего проникновения. }\end{array}$ \\
\hline
\end{tabular}


Таблица 4. Ограничения и факторы повышения интенсивности внедрения ІоТ-технологий в здравоохранение

\begin{tabular}{|c|c|}
\hline Факторы роста и развития & Ограничивающие факторы \\
\hline $\begin{array}{l}\text { - снижение совокупных затрат на лечение; } \\
\text { - формирование нового уровнякачества в диагно- } \\
\text { стике заболеваний, мониторинге состояния больного, } \\
\text { получении квалифицированных консультаций; } \\
\text { - рост эффективности управления запасами (меди- } \\
\text { каментами, перевязочными материалами и т.д.) и } \\
\text { медицинским оборудованием, в том числе перенос- } \\
\text { ным; } \\
\text { - повышение контроля и оптимизация нагрузки } \\
\text { медицинского персонала. }\end{array}$ & $\begin{array}{l}\text { - слаборазвитая правовая база: } \\
\text { по внедрению дистанционных медицинских услуг; } \\
\text { по сертификации и стандартизацииІоТ-устройств } \\
\text { по защите персональных медицинских данных, } \\
\text { средств телекоммуникации; } \\
\text { - кибербезопасность, защита каналов связи, переда- } \\
\text { ющих устройств; } \\
\text { - высокое техническое качество, разрешение } \\
\text { устройств, необходимых в медицинской деятельно- } \\
\text { сти; } \\
\text { - социальные устои, связанные с непринятием в } \\
\text { социуме и профессиональной среде результатив- } \\
\text { ность лечения, постановки диагноза, мониторинга на } \\
\text { расстоянии; } \\
\text { - ограниченное число специалистов по обслужива- } \\
\text { нию цифровых медицинских устройств; } \\
\text { - высокая стоимость на импортные медицинские } \\
\text { информационно-цифровые приборы и устройства } \\
\text { при отсутствии отечественных аналоговІо-у- } \\
\text { стройств. }\end{array}$ \\
\hline
\end{tabular}

Таблица 5. Ограничения и факторы повышения интенсивности внедрения ІоТ-технологий в сельское хозяйство

\begin{tabular}{|c|c|}
\hline Факторы роста и развития & Ограничивающие факторы \\
\hline $\begin{array}{l}\text { - снижение потерь зерна, ГСМ, удобрений, воды и } \\
\text { других ресурсов; } \\
\text { - снижение числа рабочих мест и затрат на оплату } \\
\text { труда. } \\
\text { - повышение урожайности, продуктивности живот- } \\
\text { ных и птицы }\end{array}$ & $\begin{array}{l}\text { - отсутствие возможности передавать сигнал и ин- } \\
\text { формацию с полей и удалённых территорий, слабо- } \\
\text { развитая инфраструктура, низкий уровень покрытия } \\
\text { телекоммуникационными сетями; } \\
\text { - специфичность сельскохозяйственной деятельно- } \\
\text { сти, требующая постоянно введения индивидуаль- } \\
\text { ных настроек, что является технологически сложным, } \\
\text { учитывая удалённость сельхоз объектов и большие } \\
\text { расстояния; } \\
\text { - низкий уровень заработной платы, нивелиру- } \\
\text { ющий все возможные экономические эффекты от } \\
\text { внедренияІоТ-технологий; } \\
\text { - суммарная величина инвестиций при внедрении } \\
\text { ІоТ-технологий не совместима с объёмами выруч- } \\
\text { ки и прибыли большинства сельскохозяйственных } \\
\text { организаций. }\end{array}$ \\
\hline
\end{tabular}

Таблица 6. Ограничения и факторы повышения интенсивности внедрения ІоТ-технологий в логистику

\begin{tabular}{|l|l|}
\hline \multicolumn{1}{|c|}{ Факторы роста и развития } & \multicolumn{1}{|c|}{ Ограничивающие факторы } \\
\hline - получение информации о всех перемещаемых & - высокий уровень инвестиций по внедрени- \\
объектах, состоянии агрегатов в режиме онлайн & юІоТ-технологий; \\
- минимизация запасов, складских расходов; & - доступность и дешевизна рабочей силы слабо \\
- контроль за состоянием объектов инфраструкту- & стимулирует внедрение ІоТ технологий; \\
ры в режиме реального времени (объём нагрузки, & - сложные природно-климатические условия стра- \\
наличие трещин, повреждений на агрегатах, узлах, & ны (температурные перепады, большая протяжён- \\
оборудовании); & ность пути следования внутренних грузов и т.д.); \\
- формирование аналитической базы данных, с це- & - не развитая (устаревшая) инфраструктурадля вне- \\
лью предотвращения поломок, аварий, внештатных & дрения цифровых технологий. \\
ситуаций и их анализа; & \\
- рост объективности и эффективности системы & \\
стимулирования работников организаций. & \\
- повышение степени контроля за действиями & \\
сотрудников, профилактика краж, несанкциониро- & \\
ванного использования основных средств и иных & \\
активов организации. & \\
\hline
\end{tabular}


Таблица 7. Ограничения и факторы повышения интенсивности внедрения ІоТ-технологий в городскую среду

\begin{tabular}{|c|c|}
\hline Факторы роста и развития & Ограничивающие факторы \\
\hline $\begin{array}{l}\text { - снижение количества автомобильных пробок; } \\
\text { - уменьшение времени ожидания общественного } \\
\text { транспорта; } \\
\text { - сокращение потерь и потребления воды, электри- } \\
\text { чества, тепловой энергии, за счёт датчиков уровня } \\
\text { освещённости, влажности, температуры и других } \\
\text { IоТ-устройств; } \\
\text { - сокращение числа аварий в системах жизнеобе- } \\
\text { спечения, ЖКХ, благодаря мониторингу оборудова- } \\
\text { ния, его состояния, оценки уровня износа; } \\
\text { - снижение уровня загазованности, улучшения эко- } \\
\text { логической обстановки; } \\
\text { - улучшение работы экстренных служб; } \\
\text { - снижение уровня преступности, повышение рас- } \\
\text { крываемости совершённых преступлений; } \\
\text { - укрепление здоровья жителей города. }\end{array}$ & $\begin{array}{l}\text { - высокая стоимость внедрения ІоТ-технологий и } \\
\text { обслуживания систем; } \\
\text { - ограниченное количество специалистов в сфере } \\
\text { ІоТ-технологий; } \\
\text { - проблема совместимости ІоТ- платформ с пара- } \\
\text { метрами действующих информационных систем в } \\
\text { городах; } \\
\text { - дефицитность бюджетов большинства городов } \\
\text { Российской Федерации. }\end{array}$ \\
\hline
\end{tabular}

Таблица 8. Ограничения и факторы повышения интенсивности внедрения ІоТ-технологий собственниками жилья в Российской Федерации

\begin{tabular}{|c|c|}
\hline Факторы роста и развития & Ограничивающие факторы \\
\hline $\begin{array}{l}\text { 1. контроль } \\
\text { a) за использованием ресурсов (воды, электричества, } \\
\text { тепла); } \\
\text { б) за окружающей средой (территорией, домашни- } \\
\text { ми животными), включает установку сигнализации, } \\
\text { видеонаблюдения, датчиков протечек воды, датчи- } \\
\text { ков движения, закрытия и открытия дверей и окон и } \\
\text { других устройств; } \\
\text { 2. комфорт (удалённое управление уборкой, контроль } \\
\text { за качеством воздуха, контроль за влажностью) }\end{array}$ & $\begin{array}{l}\text { - недостаток соответствующих технических специа- } \\
\text { листов по установке и обслуживанию систем; } \\
\text { - высокая стоимость установки и обслуживания } \\
\text { ІоТ-технологий; } \\
\text { - низкий уровень доходов граждан Российской } \\
\text { Федерации в сравнении с уровнем дохода граждан } \\
\text { высокотехнологичных государств мира; } \\
\text { - низкий уровень заработной платы персонала, ока- } \\
\text { зываюего аналогичные услуги по уборке и обслу- } \\
\text { живанию помещений; } \\
\text { - кибер угрозы по взлому систем управления и по- } \\
\text { лучения конфиденциальной информации о частной } \\
\text { жизни; } \\
\text { - перестройка или капитальный ремонт при вне-- } \\
\text { дрении технологий в построенный ранее дом. }\end{array}$ \\
\hline
\end{tabular}

кран, электричество, закрыть окна, выключить утюг, износился элемент электро или водо сетей.

Цифровые технологии являются реальностью современного мира, государства, пренебрегающие этим фактом, столкнуться с технологическим отставанием и необходимостью уплачивать интеллектуальную ренту странам производителям высокотехнологичных устройств.

Внедрение цифровых технологий в экономику государства, создание стимулов для применения технологий больших данных, интерне- та вещей хозяйствующими субъектами должно стать первостепенной задачей любого государства, поскольку данные технологии улучшают уровень и продолжительность жизни, повышают эффектность производств и использования ресурсов.

Поэтому необходимо развивать собственные центры создания цифровых технологий, организуя результативную кадровую политику, производственно-технологическую, законодательную, повышая уровень жизни граждан своей страны.

\section{Библиографический список}

1. Вершинина, И.А. «Умные» города: перспективы появления и развития в России//Вестник Московского университета. Серия 18: «Социология и политология». 2016. № 2. С.163-175. 
2. Маркеева, А.В. Экономика участия (Sharingeconomy): проблемы и перспективы развития// Инновации.№ 8 (226). 2017. С. 73-78.

3. Мясоедов С.А. Драйверы и ограничения развития технологий BigData // Социально-экономическое развитие России: материалы Всерос. науч. конф. (Чебоксары, 28 июня 2019 г.) / редкол.: К.Г. Яковлев [и др.] - Чебоксары: ИД «Среда», 2019.

4. Мясоедов С.А. Экономическая сегментация цифровой экономики// Вестник ИМСИТа: научноинформационный и учебно-методический журнал.- Краснодар: типография ИМСИТ - 2019._№ 1(77).C. 8-11.

5. Digital in 2017: Global Overview. https:/wearesocial.com/sg/ blog/2017/01/digital-in-2017-global-overview

6. J. J. Horton, R. J. Zeckhauser. Owning, usingandrenting: some simple economics of the «sharing economy»//National Bureau of economic research. Cambridge, MA 02138. Workingpaper. 22029. February 2016. P. 36. 